\title{
O Significado da ação política em Hannah Arendt
}

\author{
The meaning of political action in Hannah Arendt
}

DOI: $10.20873 / \mathrm{rpv} 6 \mathrm{n} 2-10$

\section{José Eronides de Sousa Pequeno Junior}

Orcid: 0000-0001-8103-8905

Email: juniordireitouft@gmail.com

\begin{abstract}
Resumo
O presente artigo apresenta as principais distinções feitas por Arendt em torno do seu conceito de ação, assim como debate as críticas a respeito da irrelevância do conceito de ação, e seu distanciamento da política real. As críticas ao conceito de ação política debatidas no artigo partiram de Jürgen Habermas e Martin Jay. 0 primeiro acusa Arendt de equiparar a ação estratégica à instrumental, e, portanto, situá-la fora do âmbito político, o segundo autor vai mais longe e acusa Arendt de elaborar uma concepção tão heroica de ação que compartilharia uma das faces mais sinistras do totalitarismo, sua indiferença para com considerações utilitárias. Porém, tais interpretações não condizem com os textos de Arendt. Neles, ela não descarta elementos de intencionalidade e causalidade presentes em qualquer ação humana.
\end{abstract}

\section{Palavras-chave}

Ação. Princípios. Intencionalidade.

\begin{abstract}
This paper presents the main distinctions made by Arendt around the concept of action, as well as debates the criticisms regarding the irrelevance of the concept of action, and its distancing from real politics. The criticism of the concept of political action discussed in the article came from the authors Jürgen Habermas and Martin Jay, the first accusing Arendt of equating strategic action with instrumental action, and therefore placing it outside the political sphere, the second author goes further and accuses Arendt to devise such a heroic conception of action that would share one of the most sinister faces of totalitarianism, its indifference to utilitarian considerations. However, such interpretations do not agree with Arendt's texts. In them, she does not discard elements of intentionality and causality present in any human action.
\end{abstract}

\section{Keywords}

Action. Principles. Intencionality. 


\section{Introdução}

As ideias de Hannah Arendt, principalmente seu conceito de ação política, têm por muito tempo levantado críticas, seja a respeito da sua irrelevância seja do distanciamento da realidade política, devido a um saudosismo para com a Grécia antiga, mais especificamente o modelo de associação política da cidade-estado Atenas que ganha seu apogeu no período de Péricles. Fato é que as suas noções de condição humana e das atividades que a correspondem: trabalho, obra e ação estão arraigados em uma divisão um tanto controversa presente na vida do cidadão ateniense entre o público e o privado, entre o ambiente doméstico e a ágora.

Essas críticas giram em torno principalmente de uma distinção atribuída a Arendt muito rígida entre economia e política, de que a atividade política seria desprovida de preocupações econômicas, e até mesmo de que a ação política seria desprovida de considerações instrumentais e até estratégicas. Não haveria espaço para a política real, repleta de artimanhas, manipulações e conflitos de interesses. Certo é que Arendt alerta para os perigos de uma instrumentalização da ação e para o consequente declínio da esfera pública. Mas será que esse alerta a levou a excluir do espaço público e dos assuntos humanos qualquer instrumentalização da ação, a ponto de excluir elementos constitutivos de toda ação humana como os motivos e os objetivos que guiam e direcionam nossas práticas? Não haveria espaço para ações estratégicas e preocupações econômicas no debate público?

Neste artigo, pretendo apresentar as principais distinções feitas por Arendt em torno do seu conceito de ação, assim como debater as críticas a respeito da irrelevância do conceito de ação, e seu distanciamento da política real. Os textos de Arendt autorizam uma concepção de ação desprovida de motivos e de objetivos e uma delimitação tão rigorosa entre preocupações políticas e econômicas? E caso os escritos dela não autorizem tal interpretação ainda caberia alguma crítica a respeito da sua delimitação do domínio da política e da economia? 0 artigo se divide da seguinte maneira: primeiramente apresento as críticas feitas ao conceito de ação de Hannah Arendt e para isso lanço mão do texto "O Conceito de Poder de Hannah Arendt" de 
Jürgen Habermas; depois, apresento a concepção de Arendt da condição humana e como ela nos impele para as atividades da ação, da obra e do trabalho. Depois, discuto os elementos principais da ação, como a condição humana da pluralidade, a capacidade reveladora da ação, a teia de relações humanas, isso para apresentar a duas dimensões da ação humana: a agonística e a consensulatista. Entender essas duas dimensões e como elas se relacionam nos impede de enveredar por interpretações tortuosas dos escritos de Arendt que excluam da sua concepção de ação política qualquer consideração instrumental e estratégica. Por fim, respondo à indagação de se ao incorporar ao seu conceito de ação considerações estratégicas ainda caberia crítica a respeito da sua delimitação do domínio da política e da economia.

\section{Habermas}

O texto "O Conceito de Poder de Hannah Arendt”, de Jürgen Habermas, é particularmente interessante por combinar a apreciação correta do método fenomenológico de Arendt e sua descrição do processo de gestação do poder, a partir do que ele chama de estruturas intatas da intersubjetividade, e uma interpretação incompatível com os textos de Arendt da ação desprovida de qualquer elemento estratégico.

Habermas concentra o texto em três momentos. No primeiro, ele demonstra como Arendt introduziu e fundamentou o conceito de poder. No segundo, mostra como ela aplicou o conceito em situações extremas. No último, Habermas explora pontos vulneráveis.

Habermas acusa Arendt de excluir o elemento estratégico da ação de suas ponderações políticas. A condução da guerra, por exemplo, é o modelo clássico da ação estratégica. A atividade bélica envolve a utilização de meios calculados de violência, seja para intimidar ou para destruir o adversário. Pela semelhança que esta ação possui com a instrumentalização dos meios para a produção de objetos, Arendt equipara a ação estratégica à instrumental e a situa fora do âmbito político. Entretanto, a ação estratégica se manifesta com frequência no âmbito político, na constante luta pelo poder e em uma interação social que não visa a um entendimento mútuo, mas sim ao êxito. 
Segundo Habermas, a divisão rígida que ela efetua entre a política e o social, público e privado, liberdade e bem-estar não pode ser aplicada à moderna sociedade burguesa e ao Estado moderno. Ela é praticamente inaplicável nas condições modernas, pois:

um Estado, exonerado da elaboração administrativa de matérias sociais; uma política, depurada das questões relativas à política social; uma institucionalização da liberdade pública, que independe da organização do bem-estar; um processo radical de formação democrática da vontade, que se abstém em face da repressão social- este não é um caminho viável para nenhuma sociedade moderna. (HABERMAS, 1980, p. 110)

A conclusão de Habermas é que o conceito comunicativo de poder de Arendt desvenda certos fenômenos-limite do mundo moderno, para os quais a ciência política se tornou, em grande parte, insensível; por outro lado, tal conceito define uma concepção da política que leva a contrassensos. A inadequação da concepção política de Arendt se dá pela exclusão da competição estratégica pelo poder político, tornando-a distante da realidade, não explicando a concorrência pelo poder. Porém, tal interpretação não é autorizada pelos textos de Arendt.

\section{Ação política}

A proposta de Arendt é investigar, pensar o que estamos fazendo. Em A Condição Humana, Hannah Arendt voltou seu foco para a experiência do convívio humano e isso a permitiu desenvolver categorias inovadoras que colocaram a experiência humana em uma perspectiva de resgate da dignidade da política. A vita activa no seu pensamento ganha importância e dignidade próprias ao não se encontrar mais submetida às categorias da vita contemplativa. Arendt, sempre em A Condição Humana, procurou ainda compreender como a tradição europeia contribuiu para o estabelecimento de um mundo cujos valores são ditados pela atividade do trabalho. Nessa obra, ao resgatar a noção de vita activa, ela elabora a original distinção entre trabalho, obra e ação, situando a política na ação, na qual a liberdade se manifesta, em contraposição à atividade do trabalho, dominada pelas necessidades do corpo e da vida.

Arendt recorre à tradição de pensamento que considerava a polis grega como locus do surgimento da política. É precisamente na polis grega que a ação e o discurso se tornam a única forma legítima de decidir os rumos daquilo que é comum a todos os cidadãos. A polis grega 
possuía essencialmente duas funções: em primeiro lugar, era a constituição de um espaço no qual os homens poderiam fazer de modo permanente aquilo que de outra forma só poderiam fazer esporadicamente, qual seja a comparticipação de atos e palavras. Em segundo lugar, estava a imortalização dos grandes feitos e palavras, pois, do contrário, os atos e as palavras poderiam ser esquecidos.

Para adentrar neste espaço constituído pela polis, era necessário vencer uma batalha que se dava em um espaço pré-político ou mesmo antipolítico. Era necessário que o homem se desvencilhasse das obrigações que as necessidades da vida impõem a cada indivíduo. 0 local onde se dava esta batalha era a família. A polis era exatamente o oposto do oikos (lar) do cidadão grego. Os indivíduos constituíam seus lares pela necessidade que a vida os impunha, visando a manutenção da vida individual e da espécie. Já a polis era constituída visando a liberdade e a fama imortal.

A distinção entre a polis e a família era a mesma entre a esfera pública e a privada. 0 termo público possuía dois significados: o primeiro era o de que "tudo que vem a público pode ser visto e ouvido por todos e tem a maior divulgação possível” (ARENDT, 2005a, p. 59), ou seja, o público enquanto aparência. O segundo significado aponta para o termo público como o mundo comum, ou seja, aquilo que é construído para estar entre os homens, para mediar suas relações. Já o termo privado possuía uma conotação negativa, de privação de um espaço no qual se pode ver e ser visto por outros, privado de um mundo comum, e privado da possibilidade de realizar feitos que possam ser imortalizados. 0 termo privado, também significava que o homem possuía um lugar no mundo. No mundo grego, o público estava associado a polis e o termo privado estava associado à família.

É a partir dessa divisão entre público e privado que Arendt desenvolve seus conceitos de trabalho, obra e ação. Em que as atividades do trabalho e da fabricação eram próprias ou correspondiam ao ambiente privado, e as condições humanas as quais estavam ligadas eram próprias aos indivíduos enquanto pertencente a uma mesma espécie ou enquanto fabricantes do mundo, uma atividade a ser desenvolvida de forma solitária, que não depende da presença de outros. Porém, a ação era uma atividade a ser desenvolvida em público, por depender da presença de outros e só pode existir diante da condição de pluralidade humana. 
Arendt concebe a ação como uma atividade essencialmente humana e política, que só se efetiva através da condição humana da pluralidade. Tal condição de pluralidade corresponde "ao fato de que homens, e não o Homem, vivem na Terra e habitam o mundo" (ARENDT, 2005a, p.15). Isto quer dizer que os homens não são meras cópias de uma ideia abstrata de Homem. Compartilhamos semelhança enquanto espécie, porém nos distinguimos como indivíduos, todo ser humano ao nascer traz um início, uma potencialidade de trazer o novo ao mundo, e essa potencialidade somente se realiza em conjunto, em associação com outros indivíduos.

Arendt não limita a ação a simples afirmação de liberdade pública ou felicidade pública, seu carácter é radicalmente inovador. Até mesmo a liberdade tradicionalmente situada no império da vontade necessita ser reformulada. Essa é a razão para a ênfase que Arendt concede à ação para a reconstrução de um mundo pós-totalitário, mundo este marcado pela ruptura com a tradição de pensamento político ocidental. A ação nada mais é do que o início de algo totalmente inédito, e esse início se dá com o nascimento do homem, pois ele é o próprio início, a fonte de toda novidade no mundo, e isto porque ele próprio é um ser singular, diferente de todos os que existiram antes dele.

Mas de que modo o homem age e revela sua singularidade? 0 homem age ao tomar iniciativa em relação a uma determinada questão ou situação, e essa iniciativa pode trazer a existência algo completamente novo para o mundo, que nunca existiu até então. Trata-se de uma compreensão que Arendt resgata de Santo Agostinho, que compreendia o homem como um iniciador, alguém que traz ao mundo a novidade, por ser ele próprio um ser singular, diferente de todos os que existiram antes dele. E a revelação se dá através do discurso, é por meio dele que o agente anuncia o que fez e o que pretende fazer, e assim passamos a conhecer o autor do ato.

A iniciativa da ação não é de forma alguma imposta pela necessidade como é o caso do trabalho, nem obedece a uma regra de utilidade, como acontece na fabricação. Ela, no máximo, pode ser estimulada pela presença de outras pessoas. 0 ímpeto que possuímos para nos inserirmos em um mundo de comparticipação de atos e palavras vem do nosso nascimento. Cada pessoa, ao nascer, é ela própria um início (ARENDT, 2005a, p. 190). Não é apenas uma continuidade do início do mundo, mas se constitui em um início completamente novo que perdura mesmo após a morte daquele que o iniciou. Ação, em termos gerais, não significa apenas 
comportamento ou uma atitude em vista de um fim, significa, antes, iniciativa, imprimir movimento a alguma coisa.

Essa capacidade inovadora da ação, que transcende motivos e objetivos humanos, acentuada por Arendt, é uma noção mal compreendida por autores como Martin Jay, para quem o esforço de Arendt em dar autonomia à ação diante de fatores econômicos a levou a uma concepção de ação pura, desprovida de restrições normativas e instrumentais. Martin Jay chega a acusar Arendt de elaborar uma concepção tão heroica de ação que, paradoxalmente, implica em uma das faces mais sinistras do totalitarismo, a sua feição não utilitária:

one of the most sinister characteristics of totalitarian systems, best shown in the Nazi attitude toward the Jews, is their indifference to utilitarian considerations. A politics that is oblivious to the meansends continuum and the consequences of its actions risks descending into the realm of fantasy in which the inexorable logic of an ideology can justify even self-destructive behavior. The "expressive" moment of politics need not be seen as the absolute negation of the instrument. (JAY, 1980, p. 364)

A capacidade da ação de transcender motivos e objetivos não a torna desprovida de motivos e objetivos. Um olhar cuidadoso na passagem abaixo nos permite esclarecer alguns pontos:

A ação, na medida em que é livre, não se encontra nem sob a direção do intelecto, nem debaixo dos ditames da vontade - embora necessite de ambos para a execução de um objetivo qualquer -; ela brota de algo inteiramente diverso que, seguindo a famosa análise das formas de governo por Montesquieu, chamarei de um princípio. Princípios não operam no interior do eu como o fazem motivos - "a minha própria perversidade", ou meu "justo equilíbrio" -, mas como que inspiram do exterior, e são demasiado gerais para prescreverem metas particulares, embora todo desígnio possa ser julgado à luz de seu princípio uma vez começado o ato. Pois, ao contrário do juízo do intelecto que precede a ação e do império da vontade que a inicia, o princípio inspirador torna-se plenamente manifesto somente no próprio ato realizador; e contudo, ao passo que os méritos do juízo perdem sua validade e o vigor da vontade imperante se exaure, no transcurso do ato que executam em colaboração, o princípio que o inspirou nada perde em vigor e em validade através da execução. Distintamente de sua meta, o princípio de uma ação pode sempre ser repetido mais uma vez, sendo inexaurível, e, diferentemente de seu motivo, a validade de um princípio é universal, não se ligando a nenhuma pessoa ou grupo em especial. Entretanto, a manifestação de princípios somente se dá através da ação, e eles se manifestam no mundo enquanto dura a ação e não mais. (ARENDT, 2005b, p. 194)

Esse trecho de Sobre a Revolução nos dá um bom exemplo de como Arendt não descarta da ação livre categorias de meios e fins, pois, para formular que a ação é preciso o intelecto e a vontade para a realização de objetivos; assim como não descarta que as ações visem a fins e 
estejam ligadas a motivos dos mais diversos possíveis. Não se encontrar sob a direção do intelecto, nem debaixo dos ditames da vontade, significa que o sentido da ação transcende a mera realização de objetivos e não pode ser explicada apenas por uma relação de causalidade com os motivos. A distinção entre significado da ação e a sua instrumentalidade é a chave para evitar a confusão estabelecida por alguns intérpretes de Arendt.

\section{A distinção entre significado da ação e a sua instrumentalização}

O que Arendt busca evitar é que a política e a ação sejam interpretadas, ou melhor, tenham seus significados e importância, em função do quanto elas conseguem maximizar propósitos e objetivos aos quais servem. 0 significado da ação pode ser extraído do que Arendt chama de princípios. De alguma forma, a ação está atrelada a esses princípios que ela mesma manifesta. A ação brota, então, do que Arendt chama de princípios. Princípios não são como os motivos e as intenções, pois são externos ao indivíduo. E embora sejam tão gerais que não possam prescrever metas, as ações são sempre julgadas de acordos com seus princípios. Diferentemente do objetivo a ser atingido com a ação, os princípios só sobrevivem enquanto dura a ação, possuem uma validade universal, pois não estão ligados às circunstâncias, nem se esgotam mesmo depois de serem repetidos diversas vezes. Arendt dá como exemplo de princípios a honra, a glória, o amor à igualdade, e o medo, a desconfiança ou o ódio (2005b, p. 195).

Além dos princípios, a ação revela um quem, pois ela é sempre acompanhada de um discurso revelador, isto é, de um discurso que revela quem o agente realmente é. Numa palavra, é através do discurso que o autor da ação se identifica e anuncia o que fez, faz e pretende fazer. Esse quem, não se resume a qualidades, características e atributos dos indivíduos, pois esses nós compartilhamos com todos, não são esses atributos que nos distinguem como autores das ações políticas. Não podemos esconder esse quem como acontece com nossas qualidades, a revelação deste está em tudo que se diz e se faz. É como se ele estivesse escondido daquele que atua e se mostrasse apenas àquele que vê a ação de fora. 0 risco é inerente à ação política, pois nunca sabemos de antemão quem iremos revelar. 
A ação jamais pode ser realizada no isolamento, pois necessita da companhia de outros assim como a obra necessita da natureza para a sua matéria-prima. Essa dependência que o homem de ação possui de seus semelhantes pode ser demonstrada no significado das duas palavras em grego para a ação. A primeira, archein, significa "começar", "ser o primeiro" e "governar"; a segunda, prattein, é "atravessar", "realizar" e "acabar" (ARENDT, 2005a, p. 202). 0 porquê de os gregos usarem duas palavras para a ação é a existência de dois momentos durante a ação. 0 primeiro, é o início provocado por uma pessoa, o segundo é a realização levada a cabo por todos aqueles que tomam parte na ação que foi desencadeada. A ação possui, portanto, duas dimensões: uma agonística e outra consensualista. A primeira, revela um individualismo extremo, um ímpeto de auto-exibição do cidadão diante de seus concidadãos, quer dizer, uma tentativa de concentrar a sua vida em um único ato que possa ser digno de ser lembrado. A segunda se torna manifesta na dependência de um cidadão para com os outros cidadãos para levar adiante sua ação.

A condição humana da ação é a pluralidade. A ação depende da constante presença de outros indivíduos, não somente após, mas durante toda a ação. E essa companhia é marcada por seres portadores de semelhanças e diferenças (ARENDT, 2005a, p. 188). Eles são iguais, pois se não guardassem certa semelhança entre si não poderiam compreender uns aos outros, e se não fossem diferentes, ou melhor singulares, não existiria nenhuma razão para o discurso ou para a ação. Esta diferença não é apenas a qualidade de alteridade, de outra existência distinta da nossa, mas é a qualidade de singularidade, de distinção.

A pluralidade humana não é apenas a condição sem a qual a política não existiria, mas é a própria razão da existência da política. A convicção dos romanos de que a pluralidade fazia parte de suas vidas era tamanha que eles identificavam a vida com o fato de estarem entre os homens e a morte com o se ausentar da companhia dos homens (ARENDT, 2005a, p. 15). Tal convicção só poderia ser resultado de suas experiências com a política e com o agir em conjunto.

Neste ponto do texto é importante salientar o caráter público da ação, pois as críticas acerca do conceito de ação nos escritos arendtianos tomam o seu conceito do ponto de vista da ação individual, sem levar em conta o seu caráter público. A ação não pode ser resumida a indivíduos fazendo certas coisas. Coisas podem ser feitas em isolamento, mas a ação nunca se dá 
nessa condição, ela só pode ocorrer em um mundo comum, mundo este caracterizado por toda sorte de artefatos e de objetos fabricados pelo ser humano, assim como pelos assuntos humanos. Arendt define esse mundo comum da seguinte forma:

O termo "público" significa o próprio mundo, na medida em que é comum a todos nós e diferente do lugar que privadamente possuímos nele. Esse mundo, contudo, não é idêntico à Terra ou à natureza, enquanto espaço limitado para o movimento dos homens e condição geral da vida orgânica. Antes, tem a ver com o artefato humano, com o que é fabricado pelas mãos humanas, assim como com os negócios realizados entre os que habitam o mundo feito pelo homem. Conviver no mundo significa essencialmente ter um mundo de coisas interposto entre os que o possuem em comum, como uma mesa se interpõe entre os que se assentam ao seu redor; pois, como todo espaço-entre [in-between], o mundo ao mesmo tempo separa e relaciona os homens entre si. (ARENDT, 2005a, p. 62)

O mundo dos artefatos humanos permite aos indivíduos a conservação de suas identidades mesmo com o passar dos anos, e ao mesmo tempo permite uma percepção de semelhança. É essa objetividade e esse senso de semelhança que nos possibilita a igualdade necessária para ação, enquanto os assuntos humanos, o mundo dos negócios humanos é a condição para singularidade e diversidade. Arendt descreve esse mundo de artefatos e de negócios humanos como um mundo que se interpõe entre os homens. Não somente se interpõe como é também a este mundo que nossas palavras e nossas ações se referem. No trecho a seguir, Arendt descreve como nossas ações e palavras não estão desvencilhadas da busca de objetivos específicos, mas que é precisamente na busca de certos objetivos que os indivíduos dão vazão aos seus atos e às suas palavras em uma teia de relações humanas; teia se sobrepõe sobre o mundo físico e mundano juntamente com os interesses ligados a ele:

A ação e o discurso ocorrem entre os homens, uma vez que a eles são dirigidos, e conservam sua capacidade de revelar o agente [agent-revealing] mesmo quando o seu conteúdo é exclusivamente "objetivo" dizendo respeito a questões do mundo das coisas no qual os homens se movem, mundo este que se interpõe fisicamente entre eles e do qual procedem seus interesses específicos, objetivos e mundanos. Esses interesses constituem, na acepção mais literal da palavra, algo que inter-essa [inter-est], que se situa entre as pessoas e que, portanto, é capaz de relacioná-las e mantê-las juntas. A maior parte da ação e do discurso diz respeito a esse espaço-entre [in-between], que varia de grupo para grupo de pessoas, de sorte que a maior parte das palavras e atos refere-se a alguma realidade objetiva mundana, além de ser um desvelamento do agente que atua e fala. Como esse desvelamento do sujeito é parte integrante do todo, até mesmo da mais "objetiva" interação, o espaço-entre físico e mundano, juntamente com os seus interesses, é recoberto e, por assim dizer, sobrelevado por outro espaço-entre inteiramente diferente, constituído de atos e palavras, cuja origem se deve unicamente ao agir e ao falar dos homens diretamente uns com os outros. Esse segundo espaço-entre subjetivo 
não é tangível, pois não há objetos tangíveis nos quais ele possa se solidificar: o processo de agir e falar não pode deixar atrás de si tais resultados e produtos finais. Mas, a despeito de toda a sua intangibilidade, o espaço-entre é tão real quanto o mundo das coisas que visivelmente temos em comum. Damos a essa realidade o nome de "teia" de relações humanas, indicando pela metáfora sua qualidade de certo modo intangível (ARENDT, 2005a, p. 195).

Existe uma mediação, mesmo que intangível, constituída por atos e palavras, a qual Arendt chama de teia de relações humanas e o motivo para isto é que os homens, ao agirem, incidem sobre outros que possuem essa mesma capacidade de agir, como que incidindo sobre uma rede de ações preexistente (cf. ARENDT, 2005a, p. 195). Essa mediação subjetiva está vinculada ao mundo que se interpõe entre os homens. Este vínculo não é como o de uma faixada ou uma superestrutura determinada por uma estrutura, como querem nos fazer acreditar os materialistas (cf. ARENDT, 2005a, p. 196). Estes últimos desprezam completamente o modo no qual os homens singularizam-se ao se manifestarem, mesmo aqueles que estão empenhados em atingir um objetivo puramente material e mundano.

A manifestação da identidade do agente e o início da ação incidem sobre a teia de relações e desencadeiam um novo processo do qual surgem histórias de vidas singulares. 0 fato de incidir sobre essa teia de relações humanas repleta de interesses divergentes é que faz com que, frequentemente, a ação não atinja o seu objetivo. Mas é também por causa dessa mediação que a ação "produz" histórias humanas (ARENDT, 2005a, p. 197). Essas histórias oriundas da ação falam mais de seus "heróis" do que propriamente de ideias ou de opiniões. E apesar de se originarem do homem, não possuem um autor, alguém que tenha total domínio sobre elas como acontece nas ficções.

A História da humanidade não poderia ser compreendida a não ser pelo conjunto de histórias singulares dos indivíduos que habitaram e que habitam o mundo. Pois, se os homens não são meras marionetes de alguém que os controla pelos bastidores, a História da humanidade também provém das ações dos homens. 0 sujeito humanidade não passa de uma abstração que não pode ser um agente ativo. Por isso, não há um autor da História, nem alguém que a controle. Segundo Arendt, essa é, possivelmente, a razão do desprezo que alguns filósofos, como Platão, sempre dedicaram aos negócios humanos. 
Platão, de fato, concebia as ações humanas como simples movimentos de fantoches controlados por alguém nos bastidores ou como um joguete de um deus. Essa atitude diante dos negócios humanos provavelmente decorre da perplexidade da qual somos tomados quando percebemos que a História, apesar de dever sua existência, não é de maneira nenhuma arquitetada pelos homens. A História não é um produto pronto e acabado feito por mãos humanas, mas é produto das ações humanas. Por isso não é criada nem possui criador.

Arendt atribui a Platão o começo da tradição do pensamento político ocidental, marcado pela perversão de verdades filosóficas ao serem introduzidas como padrões para a condução dos assuntos humanos. Ao conceber a política em termos análogos aos da fabricação, Platão elimina as potencialidades da ação no campo do pensamento político.

O que Arendt faz ao elaborar o seu conceito de ação política não é eliminar elementos de intencionalidade e causalidade presentes em qualquer ação humana, mas sim colocar os motivos e os objetivos em perspectiva, pois mesmo reconhecendo que esses estão presentes em qualquer ação humana, não são eles que devem ser destacados, mas os princípios que se manifestam a partir das ações e que as inspiram.

Por fim, ainda cabe perguntar se mesmo ao incorporar ao seu conceito de ação considerações estratégicas ainda caberia alguma crítica a respeito da sua delimitação do domínio da política e da economia. Arendt não exclui as preocupações sociais e econômicas da política, como vimos nos textos tratados anteriormente, a ação livre não é desprovida de interesses econômicos e sociais. Não há uma concepção de pureza política que elimine assuntos econômicos da pauta política. Porém tais preocupações não devem sobrepor o sentido da ação política manifesta em seus princípios.

\section{Conclusão}

O presente artigo apresentou as principais distinções feitas por Arendt em torno do seu conceito de ação, assim como debateu as críticas a respeito da irrelevância do conceito de ação, e seu distanciamento da política real. As críticas ao conceito de ação política partiram de autores como Habermas e Martin Jay. 0 primeiro acusa Arendt de equiparar a ação estratégica à 
instrumental, e, portanto, situá-la fora do âmbito político. Já o segundo, a acusa de elaborar uma concepção tão heroica de ação que compartilharia uma das faces mais sinistras do totalitarismo, a saber, a sua indiferença para com considerações utilitárias. Porém, tais interpretações não condizem com os textos de Arendt. Neles, ela não descarta elementos de intencionalidade e causalidade presentes em qualquer ação humana.

A distinção entre significado da ação e a sua instrumentalidade é a chave para evitar a confusão estabelecida por alguns intérpretes de Arendt. 0 significado da ação transcende a mera realização de objetivos e não pode ser explicada apenas por uma relação de causalidade com os motivos. 0 que Arendt faz, ao elaborar o seu conceito de ação política, não é eliminar elementos de intencionalidade e causalidade presentes em qualquer ação humana, mas colocar os motivos e os objetivos em perspectiva, pois mesmo reconhecendo que estes estão presentes em qualquer ação humana, os princípios que inspiram as ações devem se sobrepor aos interesses dos indivíduos. Não é uma substituição dos motivos e objetivos por princípios. 0 modelo de ação de Arendt pode ser descrito como um sujeito que visa uma finalidade e toma um posicionamento público, inspirado por um determinado princípio. Princípios não são como os motivos e as intenções, pois são externos ao indivíduo. E são tão gerais que não são capazes de prescrever metas, mas servem sempre de base para o juízo sobre as ações.

\section{Referências}

ARENDT, H. A Condição Humana. Rio de Janeiro: Forense Universitária, 2005a.

ARENDT, H. Entre o Passado e o Futuro. São Paulo: Perspectiva, 2005b.

ARENDT, H. Sobre a Revolução. Trad. D. Bottmann. São Paulo: Companhia das Letras, 2011.

HABERMAS, J. O Conceito de Poder de Hannah Arendt. In: FREITAG, B.; ROUANET, J. P. (Orgs.). Habermas. São Paulo: Ática, 1980.

JAY, M.; BOTSTEIN, L. Hannah Arendt: opposing views. Partisan Review New Brunswick, NJ, v. 45, n. 3, p. 348-368, 1978.

KNAUER, J. T. Motive and goal in Hannah Arendt's concept of political action. American Political Science Review, v. 74, n. 3, p. 721-733, 1980. 


\section{José Eronides de Sousa Pequeno Junior}

Professor da Universidade Estadual do Tocantins (Unitins). Graduado em Direito pela Universidade Federal do Tocantins (UFT), mestre em Ciência Política pela Universidade Federal do Pará (UFPA) e doutor em Ciência Política pela Universidade Federal de Pernambuco (UFPE). Tem experiência na área de Ciência Política, com ênfase em Teoria Política, atuando principalmente nos seguintes temas: democracia; ética; teoria política clássica; judiciário; comportamento político; governança eleitoral. 